\title{
Sensitivity and Specificity Determinations with Isoelectric Focusing Fractions of Blastomyces dermatitidis for Antibody Detection in Serum Specimens from Infected Dogs
}

\author{
Joshua C. Wright, Terrick E. Harrild, Gene M. Scalarone \\ Department of Biological Sciences, Idaho State University, Pocatello, USA \\ Email: wrigjos2@isu.edu
}

Received September 12, 2012; revised October 17, 2012; accepted November 6, 2012

\begin{abstract}
Blastomycosis and histoplasmosis manifest as lung and systemic fungal infections in mammals caused by Histoplasma capsulatum, and Blastomyces dermatitidis. These infections exhibit cross reactivity of antibodies which makes a correct diagnosis potentially elusive. The purpose of this study was to gain an understanding of which isoelectric focusing fractions (Rotofor ${ }^{\mathrm{TM}}$ ) of $B$. dermatitidis were reactive or cross reactive with serum specimens from dogs infected with $B$. dermatitidis $H$. capsulatum, and Cryptococcus neoformans. Three serum specimens from dogs that were infected with $B$. dermatitidis, two dogs infected with $H$. capsulatum, and one dog infected with $C$. neoformans were assayed against the 20 B. dermatitidis Rotofor ${ }^{\mathrm{TM}}$ fractions. Reactivity was determined using the indirect enzyme linked immunoassay (ELISA). Reactivity with B. dermatitidis was found predominantly in the protein fractions 1 - 6, and cross reactivity with $H$. capsulatum, and C. neoformans sera was found within the B. dermatitidis protein fractions 15 - 19 .
\end{abstract}

Keywords: Isoelectric Focusing; ELISA; Blastomycosis; Lysate Antigen; Antibody Detection

\section{Introduction}

Blastomycosis is a systemic fungal infection of humans and animals that is initiated by the inhalation of conidia (spores produced by the filamentous phase of the fungus). The organism exists in this stage in nature or in the laboratory at $25^{\circ} \mathrm{C}$ and has the ability to convert to the yeast phase at $37^{\circ} \mathrm{C}$ in the lungs of the infected host. The disease may be self-resolving or it may exist as an acute or chronic state in the pulmonary tissue, where it may be misdiagnosed as tuberculosis. If the disease is not diagnosed or left untreated while in the lungs it may become invasive, and disseminate to other organs, and possibly to the central nervous system where fatal meningitis may develop [1-5]. Blastomycosis, as well as other systemic mycoses, are termed "emerging fungal threats" since they can not only infect persons with normal immune systems, but also they are a cause for concern in individuals with AIDS or other deficiency diseases that compromise the immune system $[3,4,6]$.

Traditionally the geographic distribution of blastomycosis has been associated with southeastern and southcentral states that border the Ohio and Mississippi Rivers and upper Midwestern states including areas in Wisconsin and Minnesota, which are highly endemic for the disease. Recent studies have indicated that blastomycosis may be present in other regions with sporadic cases being reported in Colorado, Texas, Kansas and Nebraska [1,2,5].

Due to the increase in systemic fungal diseases researchers have begun to devote more attention to developing ways of diagnosing, preventing and treating these mycoses. The greatest problem that we face at present is that a considerable amount of research and development activities are needed if we are going to have a positive impact on this situation. For the past several years the thrust of research in our laboratory has been associated with studies on various strains of $B$. dermatitidis from human, animal or environmental specimens from many geographical locations in an effort to better understand the immunobiology of the organism. Diagnosis of the disease has presented major problems. In some instances culturing or histopathological examination may be beneficial, but in some patients these methods may not yield the desired results. This has led to more and more work being done to improve immunological assays which tend to provide a more rapid diagnosis, but problems still exist with regard to the sensitivity and specificity of immunoassays [2,5,7-10]. Our laboratory has developed novel 
yeast phase lysate antigens and utilized these in various immunoassays for both antibody and antigen detection in blastomycosis [11-17], but these studies have only opened up new avenues of approach with regard to how we might improve immunodiagnostic methods in the future.

In recent years other investigators have been approaching the problem of immunodiagnosis and have produced encouraging results with antigen detection assays as second-generation assays have been developed $[7,8,10]$. Sensitivity values obtained by these researchers have generally been very good with antigen detection assays, but they evidenced less sensitivity when antibody detection assays were performed. The greatest problem that has become apparent in the majority of the investigations is the lack of specificity of the immunoassays. Our laboratory has performed a few studies on isoelectric focusing of $B$. dermatitidis yeast lysate antigens in an attempt to separate the immunoreactive and cross-reactive components of the preparations. The objective of this present study was to obtain isoelectric focusing fractions of yeast lysates and to evaluate these fractions with regard to ELISA antibody detection (reactivity vs. crossreactivity) in serum specimens from dogs with blastomycosis, histoplasmosis and cryptococcosis.

\section{Materials \& Methods}

\subsection{Antigens}

\section{Lysate Antigen Preparation}

Mycelial phase cultures of $B$. dermatitidis isolate (B5896), obtained from the Mountain Iron, Minnesota human outbreak of blastomycosis in 1999 (2), were converted to yeast cells by culturing at $37 \mathrm{C}$ on brain heart infusion agar. Yeast phase lysate reagents were prepared by a method similar to one that was previously used for the production of antigen from Histoplasma capsulatum [18-20] and modified in our laboratory for B. dermatitidis lysate antigen production [11]. The yeast phase cells were grown for 7 days at $37 \mathrm{C}$ in a chemically defined medium in an incubator shaker, harvested by centrifugation (700 × g; $5 \mathrm{~min}$ ), followed by washing with distilled water, re-suspended in distilled water and then allowed to lyse for 7 days at $37 \mathrm{C}$ in water with shaking. The preparations were centrifuged, filter sterilized, merthiolate added $(1: 10,000)$ and stored at $4 \mathrm{C}$ for further use. Protein determinations were performed on the lysates using the BCA Protein Assay Kit (Pierce Chemical Company, Rockford, IL) and dilutions of the antigenic reagents used in isoelectric focusing and ELISAsassays were based on protein concentration.

\subsection{Serum Specimens}

Serum specimens from dogs with blastomycosis, histoplasmosis, and cryptococcosiswere previously provided by Dr. A. M. Legendre (University of Tennessee College of Veterinary Medicine, Knoxville, TN).

\subsection{Isoelectric Focusing}

Isoelectric focusing was performed using the BIO-RAD Rotofor apparatus (BIO-RAD, Hercules, CA). Ampholytes (BIO-RAD) were added to the yeast phase lysate in a $2 \%$ to $98 \%$ ratio. These small charged molecules create a $\mathrm{pH}$ gradient in solution from a $\mathrm{pH}$ of 3 to 10 when an electrical current is applied so that proteins can be separated based on their isoelectric point. All proteins have a unique net charge that will force the proteins to move through the $\mathrm{pH}$ gradient until their net charge becomes zero (the isoelectric point). When proteins reach their unique isoelectric point in this $\mathrm{pH}$ gradient they are no longer able to migrate and forced to remain where their net charge is zero by the established $\mathrm{pH}$ gradient. Twenty protein fractions were collected after focusing (15 watts constant current) for approximately four hours at $4 \mathrm{C}$ to ensure that no denaturing of the proteins occurred. The focusing was stopped when the voltage stopped fluctuating $[15,16]$. After collection of the fractions the $\mathrm{pH}$ was measured and adjusted to return the proteins to their physiologically active $\mathrm{pH}$. This was accomplished by the addition of $\mathrm{HCl}$ or $\mathrm{NaOH}$ to either lower or raise the $\mathrm{pH}$ as required. Protein determinations were performed on the fractions using the Pierce BCA Protein Assay, as above.

\subsection{ELISA}

The ability of each yeast lysate reagent to detect antibodies in the above serum specimens was determined using the indirect enzyme-linked immunosorbent assay (ELISA). Each lysate antigen was diluted (2000 ng of protein $/ \mathrm{ml}$ ) in a carbonate-bicarbonate coating buffer $(\mathrm{pH}$ 9.6) and then added to triplicate wells (100 ul) of a Costar 96-well microplate (Thermo/Fisher). The plates were then incubated overnight at $4 \mathrm{C}$ in a humid chamber followed by washing three times with phosphate buffered saline containing $0.15 \%$ Tween 20 (PBS-T). The serum specimens (1:2500 dilution; $100 \mathrm{ul}$ ) were added to the microplate wells and incubated for $30 \mathrm{~min}$ at $37 \mathrm{C}$ in a humid chamber. Following this incubation the wells were washed as above and 100 ul of goat anti-dog IgG (H \& L) peroxidase conjugate (Kirkegaard and Perry, Gaithersburg, MD) was added to each well and incubated for 30 $\min$ at $37 \mathrm{C}$. The plates were again washed as above and 100 ul of peroxidase substrate (Thermo/Fisher- Pierce) was added to each well and incubated for approximately $2 \mathrm{~min}$ at room temperature. The reaction was stopped by the addition of sulfuric acid and the absorbance read at $450 \mathrm{~nm}$ using a BIO-RAD 2550 EIA reader. 


\section{Results}

\subsection{Reactivity of B5896 Protein Fractions with B. dermatitidis Dog Sera}

Figures 1-3 show that the reactivity of serum specimens from $B$. dermatitidis infected dogs against the Rotofor ${ }^{\mathrm{TM}}$ protein fractions of $B$. dermatitidis dog sera was found predominantly in the 1 - 6 range of protein fractions.

\subsection{Reactivity of B5896 Protein Fractions with H. capsulatum Dog Sera}

Figures $\mathbf{4}$ and $\mathbf{5}$ show that the cross reactivity of serum specimens from $H$. capsulatuminfected dogs against the
Rotofor $^{\mathrm{TM}}$ protein fractions of $B$. dermatitidis was found within the 15 - 20 range of protein fractions.

\subsection{Reactivity of B5896 Protein Fractions with C. neoformans Dog Serum}

Figure 6 shows that the cross reactivity of serum specimens from dogs infected with $C$. neoformans against the Rotofor $^{\mathrm{TM}}$ protein fractions of $B$. dermatitidis was found in the 15 - 19 range of protein fractions.

\section{Discussion}

B. dermatitidis, H. capsulatum, and C. neoformans are

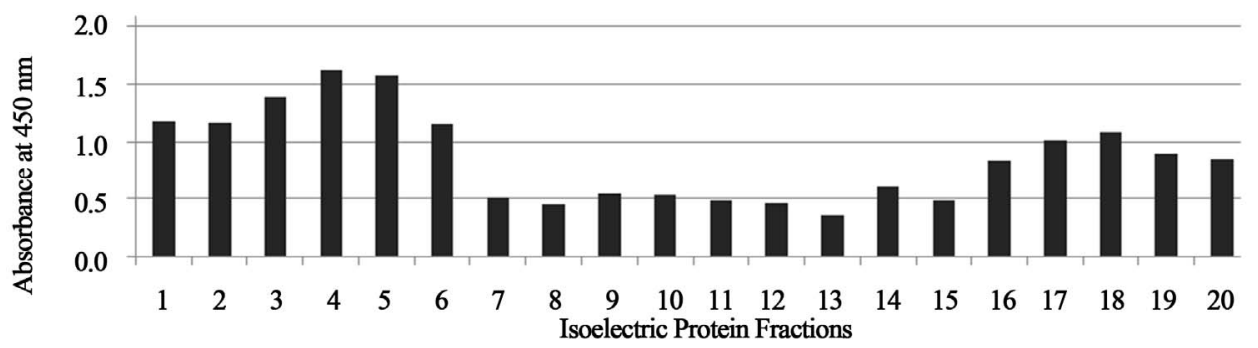

Figure 1. Absorbance values of protein fractions reacted with $B$. dermatitidis dog serum from Wisconsin.

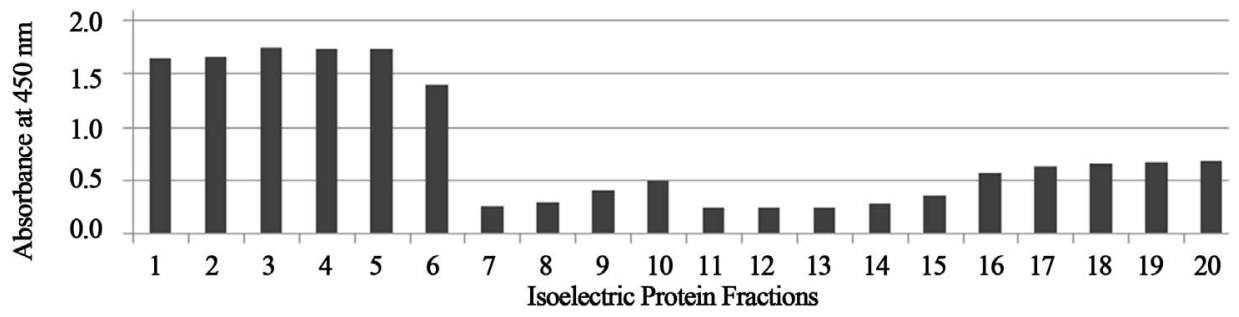

Figure 2. Absorbance values of protein fractions reacted with $B$. dermatitidis dog serum from Alabama.

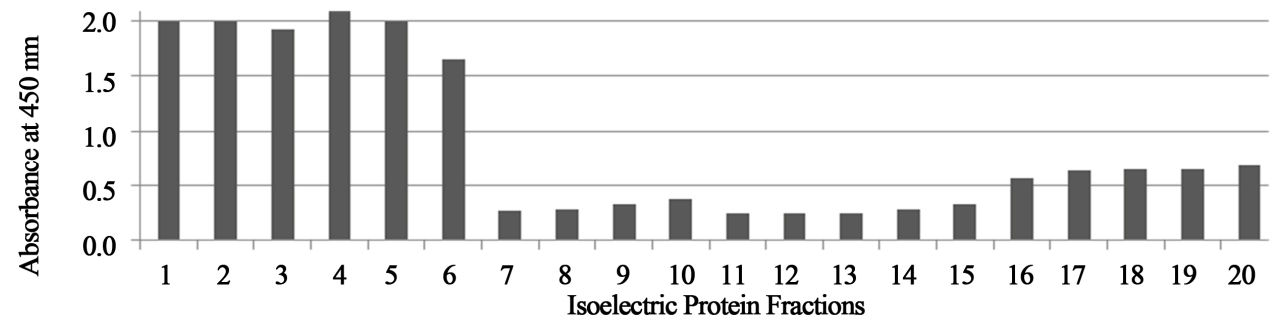

Figure 3. Absorbance values of protein fractions reacted with B. dermatitidis dog serum from Louisiana.

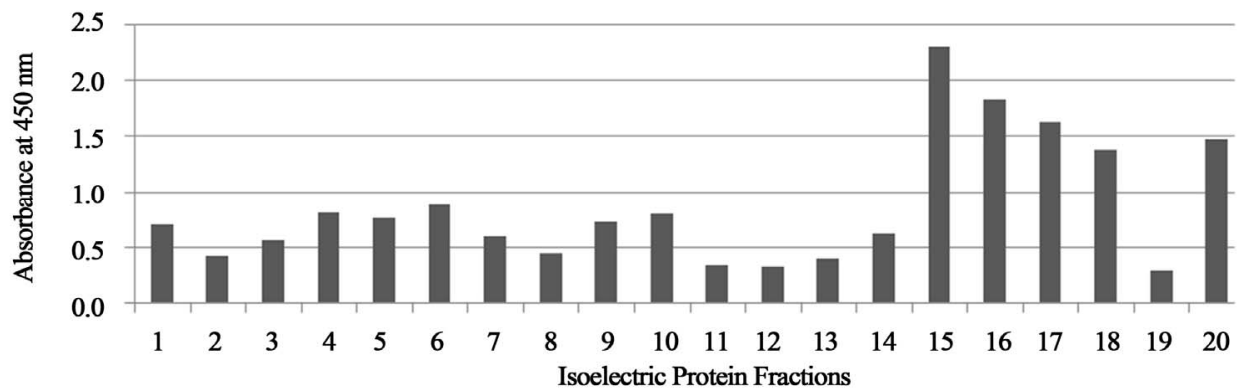

Figure 4. Absorbance values of protein fractions reacted with $H$. capsulatum dog serum (a), from Tennessee. 


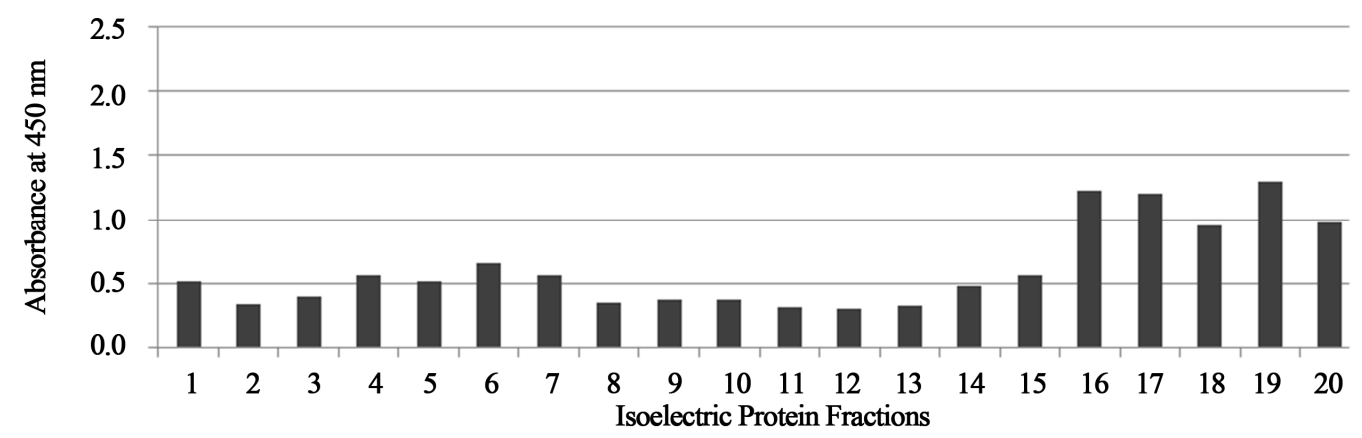

Figure 5. Absorbance values of protein fractions reacted with $\boldsymbol{H}$. capsulatum dog serum (b), from Tennessee.

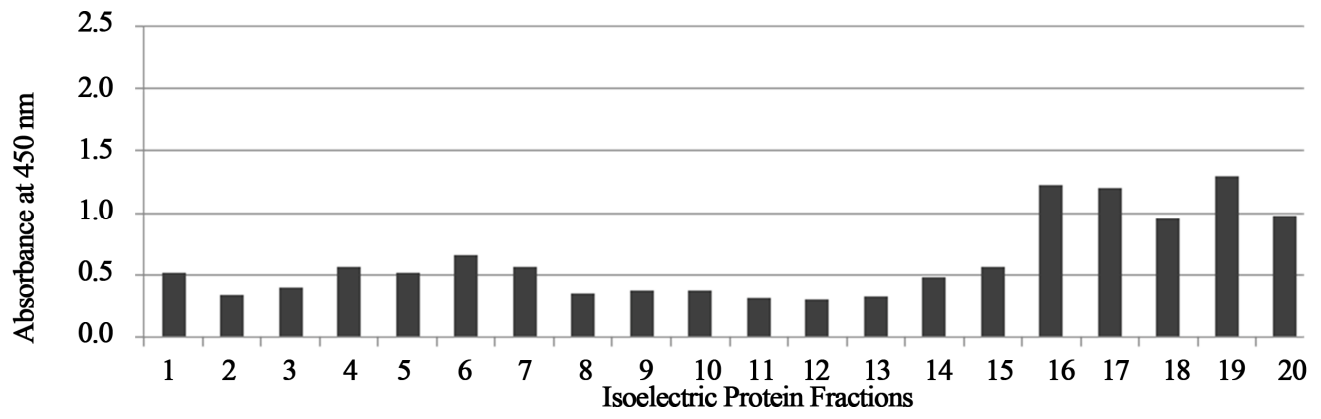

Figure 6. Absorbance values of protein fractions reacted with $C$. neoformans dog serum, from Tennessee.

endemic in the United States mainly in the Ohio and Mississippi River drainages. The antigen and serum specimens used in the study were from different geographic regions within the endemic area.The antigen used, (B5896), was from Minnesota. The dog serum specimens for $B$. dermatitidis were from Wisconsin, Louisiana, and Alabama. The dog serum specimens for $H$. capsulatum were from Tennessee and the C. neoformansdog serum specimen wasfrom Tennessee. We believethat some of the variance in the results that we recorded are related to the serum specimen's different geographic origins.

Infections involving $B$. dermatitidis, $H$. capsulatum, and $C$. neoformans in mammals exhibit cross reactivity of antibodies which makes a correct diagnosis potentially elusive. In order to elicit an accurate diagnosis, the specificity of the antigen used in a diagnostic test would need to be improved in order to either reduce or eliminate any cross reactivity of antibodies.

We observed the potential to greatly reducethe cross reactivity of $B$. dermatitidis antigen with $H$. capsulatum, and $C$. neoformans antibodiesvia isoelectric focusing of antigen proteins. Rotofor ${ }^{\mathrm{TM}}$ separation of the antigenic proteins provides an accurate means to identify and isolate the most reactive antigen protein fractions in relation to cross reactive species antibodies.

This data may prove useful regarding future studies involving additional evaluations on the detection of antibodies, or the development of a skin testing antigen(s),
[15-20] that may possibly eliminate the cross reactivity of $B$. dermatitidis to other fungal pathogens such as $C$. neoformans and $H$. capsulatum.

\section{Acknowledgements}

This research was supported by the Department of Biological Sciences, Idaho State University, Pocatello, ID 83209-8007. The B5896 Rotofor ${ }^{\mathrm{TM}}$ fractions were provided by James Hayden.

\section{REFERENCES}

[1] A. F. DiSalvo, "Blastomycosis, in Topley and Wilson's Microbiology and Microbial Infections," 9th Edition, Arnold Publishers, London, 1998, pp. 337-355.

[2] R. W. Bradsher, S. W. Chapman and P. G. Pappas, "Blastomycosis," Infectious Disease Clinics of North America, Vol. 17, No. 1, 2003, pp. 21-40. doi:10.1016/S0891-5520(02)00038-7

[3] J. R. Bariola and K. S. Vyas, "Pulmonary Blastomycosis," Seminars in Respiratory Critical Care Medicine, Vol. 32, No. 6, 2011, pp. 745-753. doi:10.1055/s-0031-1295722

[4] J. A. McKinnell and P. G. Pappas, "Blastomycosis: New Insights into Diagnosis, Prevention, and Treatment,” Clinical Chest Medicine, Vol. 30, No. 2, 2009, pp. 227-239. doi:10.1016/j.ccm.2009.02.003

[5] M. Saccente and G. L. Woods, "Clinical and Laboratory Update on Blastomycosis," Clinical Microbiology Reviews, Vol. 23, No. 2, 2010, pp. 367-381. 


\section{doi:10.1128/CMR.00056-09}

[6] J. E. Cutler, G. S. Deepe Jr. and B. S. Klein, “Advances in Combating Fungal Diseases: Vaccines on the Threshold," Nature Review of Microbiology, Vol. 5, 2007, pp. 13-18. doi:10.1038/nrmicro1537

[7] K. S. Vyas, J. R. Bariola and R. W. Bradsher, "Advances in the Serodiagnosis of Blastomycosis," Current Fungal Infection Reports, Vol. 2, No. 4, 2008, pp. 227-231. doi:10.1007/s12281-008-0033-z

[8] P. Connolly, C. A. Hage, J. R. Bariola, E. Bensadoun, M. Rodgers, R. W. Bradsher and J. J. Wheat, "Blastomyces dermatitidis Antigen Detection by Quantitative Enzyme Immunoassay," Clinical Vaccine Immunology, Vol. 19, No. 1, 2012, pp. 53-56. doi:10.1128/CVI.05248-11

[9] B. S. Klein, R. A. Squires, J. K. Lloyd, D. R. Ruge and A. M. Legendre, "Canine Antibody Response to Blastomyces dermatitidis WI-1 Antigen," American Review of Veterinary Research, Vol. 61, No. 5, 2000, pp. 554-558.

[10] D. Spector, A. M. Legendre, J. Wheat, D. Bemis, B. Rohrbach, J. Taboada and M. Durkin, “Antigen and Antibody Testing for the Diagnosis of Blastomycosis in Dogs,” Journal of Veterinary Internal Medicine, Vol. 22, No. 4, 2008, pp. 839-843. doi:10.1111/j.1939-1676.2008.0107.x

[11] S. M. Johnson and G. M. Scalarone, "Preparation and ELISA Evaluation of Blastomyces dermatitidis Yeast Phase Lysate Antigens,” Diagostic Microbiology and Infectious Diseases, Vol. 11, No. 2, 1989, pp. 81-86. doi:10.1016/0732-8893(88)90076-4

[12] J. F. Shurley, A. M. Legendre and G. M. Scalarone, "Blastomyes dermatitidis Antigen Detection in Urine Specimens from Dogs with Blastomycosis Using a Competitive Binding Inhibition ELISA,” Mycopathologia, Vol. 160, No. 2, 2005, pp. 137-142. doi:10.1007/s11046-005-3153-9

[13] C. M. Sestero and G. M. Scalarone, "Detection of IgG and IgM in Sera from Canines with Blastomycosis Using Eight Blastomyces dermatitidis Yeast Phase Lysate Anti- gens,” Mycopathologia, Vol. 162, No. 1, 2006, pp. 33-37. doi:10.1007/s11046-006-0028-7

[14] W. O. Hatch and G. M. Scalarone, "Comparison of Colorimetric and Chemiluminescent ELISAs for the Detection of Antibodies to Blastomyces dermatitidis," Journal of Medical and Biological Sciences, Vol. 3, No 1, 2009, pp. 1-6.

[15] J. L. Bono, A. M. Legendre and G. M. Scalarone, "Detection of Antibodies and Delayed Hypersensitivity with Rotofor Preparative IEF fractions of Blastomyces dermatitidis Yeast Phase Lysate Antigens,” Journal of Medical and Veterinary Mycology, Vol. 33, No. 4, 1995, pp. 209214. doi:10.1080/02681219580000441

[16] M. A. Fisher, J. L. Bono, R. O. Abuodeh, A. M. Legendre and G. M. Scalarone, "Sensitivity and Specificity of an Isoelectric Focusing Fraction of Blastomyces dermatitidis Yeast Lysate Antigen for the Detection of Canine Blastomycosis,” Mycoses, Vol. 38, No. 1, 1995, pp. 177-182. doi:10.1111/j.1439-0507.1995.tb00046.x

[17] J. F. Shurley and G. M. Scalarone, "Isoelectric Focusing and ELISA Evaluation of a Blastomyces dermatitidis Human Isolate,” Mycopathologia, Vol. 164, No. 2, 2007, pp. 73-76. doi:10.1007/s11046-007-9033-8

[18] H. B. Levine, G. M. Scalarone and S. D. Chaparas, "Preparation of Fungal Antigens and Vaccines: Studies on Coccidioides immitis and Histoplasma capsulatum," Contributions to Microbiology and Immunology, Vol. 3, 1977, pp. 106-125.

[19] G. M Scalarone, H. B. Levine and S. D. Chaparas, "Delayed Hypersensitivity Responses of Experimental Animals to Histoplasmin from the Yeast and Mycelial Phases of Histoplasma capsulatum,” Infection and Immunity, Vol. 21, No. 3, 1978, pp. 705-713.

[20] H. B. Levine, G. M. Scalarone, G. D. Campbell, R. C. Graybill and S. D. Chaparas, "Histoplasmin-CYL, a Yeast Phase Reagent in Skin Test Studies in Humans," American Review of Respiratory Diseases, Vol. 119, No. 4, 1979, pp. 629-636. 